\title{
Integration of knowledge management system for the decommissioning of nuclear facilities
}

\author{
Yukihiro IGUCHI* and Satoshi YANAGIHARA* \\ *University of Fukui \\ 4, 2-Gaiku, Kanawa-cho 1, Tsuruga-shi, Fukui-ken 914-0055, Japan \\ E-mail: iguchi-y@u-fukui.ac.jp
}

Received 22 September 2015

\begin{abstract}
The decommissioning of a nuclear facility is a long term project, handling information which begins from the design, construction and operation. Moreover, the decommissioning project is likely to be extended because of the lack of the waste disposal site especially in Japan. In this situation, because the transfer of knowledge and education to the next generation is a crucial issue, integration and implementation of a system for knowledge management is necessary in order to solve it. For this purpose, the total system of decommissioning knowledge management system (KMS) is proposed. In this system, we have to arrange, organize and systematize the data and information of the plant design, maintenance history, trouble events, waste management records etc. The collected data, information and records should be organized by computer support system e.g. data base system. It becomes a base of the explicit knowledge. Moreover, measures of extracting tacit knowledge from retiring employees are necessary. The experience of the retirees should be documented as much as possible through effective questionnaire or interview process. The integrated knowledge mentioned above should be used for the planning, implementation of dismantlement or education for the future generation.
\end{abstract}

Key words : Knowledge management, Decommissioning, Support system, Integration, Knowledge transfer

\section{Introduction}

IAEA recommended the importance of the "Nuclear Knowledge Management (NKM)" and has organized international meetings and prepared documents related to knowledge management (KM) since 2002. They are mainly for the commissioning and operation of nuclear facilities. However, KM for the decommissioning should be studied.

In Japan, based on the past experience of Power Demonstration Reactor of the Japan Atomic Energy Agency (JPDR), the decommissioning projects of power plants of Tokai, Fugen and Hamaoka 1\&2 are going on. Moreover, 6 units of Fukushima Daiichi Nuclear Power Plant will be decommissioned after the accident caused by the Great East Japan Earthquake, as well as 5 units which has decided decommissioning on March 2015.

The knowledge required at the decommissioning is different from that of construction or operation phase. It is true that knowledge of the design of the plant is necessary, but it is not all of it. Moreover, because the decommissioning is a long term project, from the beginning of the construction phase, it takes several decades until the end of the project. Then, knowledge transfer from one generation to another is necessary.

Especially in Japan, because of the social or political reasons after the Fukushima Daiichi accident, the future schedule of the decommissioning is unforeseeable. For example, the transportation of the spent fuel to the reprocessing plants is suspended and the final disposal site of the radioactive waste from decommissioning is not decided. This situation makes the projects longer and more difficult. As a result, because the employees with enough experience and knowledge are about to retire, we are obliged to consider seriously about "Knowledge Management", such as knowledge preservation, knowledge transfer and education. 


\section{Characteristics of knowledge for decommissioning}

The KM for the decommissioning activities for plants after a serious accident is quite different from that of normal plants. Basically, the KM for the plant seriously damaged by an accident is out of a scope in this paper. For the integration of KMS, we should consider the characteristics of the knowledge required for the decommissioning project. They are as follows;

$>$ Required knowledge is different from that of construction or operation phase. "Which information is really necessary for decommissioning?" This is one of the crucial knowledge.

$>$ On the other hand, decommissioning is one-time project different from cyclic operational phase.

$>$ The knowledge of the design is used in different manner in the dismantling stage, comparing the operational period.

$>$ If the knowledge is used only once, it may not be cost effective to collect and organize the knowledge.

$>$ However it is valuable if the knowledge is reusable inside the project or a similar project.

$>$ It is possible to transfer knowledge by moving staff, but it is not always rational.

$>$ On the other hand, if the knowledge about decommissioning is general enough, it is very useful and a specialized decommissioning engineering company is supposed.

$>$ For the normal decommissioning project, it is possible to implement with combination of existing technologies. In this case, the important knowledge is "Which technology is suitable?" in order to achieve it with low risk, low cost and short time.

For the records of nuclear facilities, which will be the base of the knowledge for decommissioning, an IAEA document (IAEA, 2003) says "It is clear that many of the records derived from the operation of a facility are not required for its decommissioning, but it is also clear that additional data may be necessary".

Moreover, GSR Part6 chapter 4.4 (IAEA, 2014b) says "Individuals performing decommissioning actions shall have the necessary skills, expertise and training to perform decommissioning safely. Provisions shall be made to ensure that institutional knowledge about the facility is obtained and made accessible and, as far as possible, that key staff from the facility are retained." This means if the staff during the operation and records still stay at the site, retrieval of necessary records is relatively easy. However, if the staff disappear, it will be difficult. For this reason, GSR Part6 chapter 5.1 says "The preferred decommissioning strategy shall be immediate dismantling." We have to consider characteristics mentioned above for the integration of KMS for the decommissioning.

Some studies targeting KM for decommissioning are reported in the past (Ishikura, 2009), (Ehlert, 2007), (Kirschnick and Engelhardt, 2004). However, they do not show enough experiences for our integration method of the KM. The method of appropriate management system should be studied and established as soon as possible especially in Japan.

\section{Outline of the integration approach}

A nuclear facility produces a lot of, complex, a variety of data and information during its lifetime, involving many kinds of people such as design engineers, construction, maintenance staff and operators.

The first step is to specify required data and information from the whole data and information in order to keep them as records which are essential for the decommissioning project. Moreover, not only for the information of the specific facility but also based on the international and domestic decommissioning experiences and R\&D results, important data, information, know-how and knowledge should be extracted and externalized. The knowledge is to be merged with the direct knowledge by engineers of the plant. It will finally be shared, transferred by education and training.

However, the tacit knowledge of experienced engineers is difficult to acquire. The method is discussed later. For the efficient transfer of the acquired knowledge, a support system by 3D-CAD data or Virtual Reality (VR) system is very useful (Szőke, 2014).

Based on the discussion above, the following three approach steps are proposed.

\subsection{Establishment of knowledge acquisition method necessary for decommissioning}

We should extract and arrange the required huge amount of data and information such as design, construction, operation and maintenance and domestic or international R\&D results and data and information necessary for the decommissioning. Then they should be organized and systematized for KM. Currently, for the decommissioning facilities, a set of laws, ordinances, requirements and manuals are prepared. For the each facility, a variety of computer support systems are used for decommissioning works. They contain a lot of data and information. We have to establish an efficient method to identify really required data, information and records for decommissioning, and extract essentially necessary knowledge.

\subsection{Formulation of knowledge acquisition from experienced decommissioning engineers}


It is necessary to utilize knowledge of engineers, who were engaged in design, construction, operation and maintenance, as well as knowledge and know-how of engineers who experienced the decommissioning planning and practical dismantlement. For this purpose, we have to formulate the knowledge acquisition method from skilled engineers.

\subsection{Construction of KM support system for decommissioning}

The knowledge extracted by the approaches above should be effectively utilized for the practices of decommissioning. For this purpose, the support systems should be constructed in order to support the KM of decommissioning in an efficient way. The flow of the integration of KMS discussed above is shown in Fig. 1.

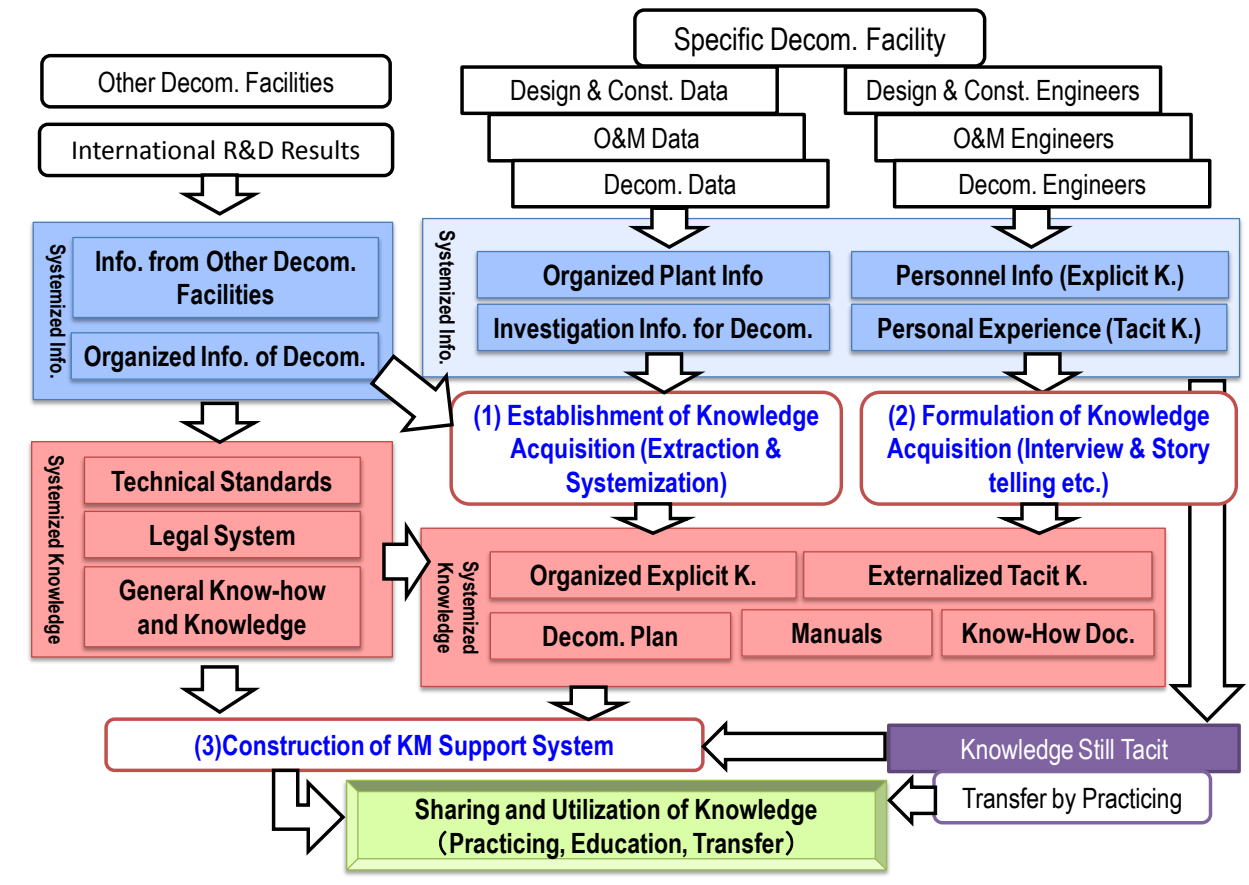

Fig. 1 Flow of integration of decommissioning KMS

\section{K.: Knowledge}

KM: Knowledge Management Decom.: Decommissioning Info.: Information

Const.: Construction

O \& M: Operation and Maintenance Doc.: Document

\section{Importance of the integration}

This integration approach is for the establishment of the method for efficient knowledge transfer to the next generation or other decommissioning facilities. This is indispensable for the nuclear power plants, especially in the decommissioning, which is a long term project and requires rational and safe practice by using helpful knowledge acquired.

NKM is an application method to utilize the KM method based on the administrative engineering. It covers mainly over the preservation and transfer of expert knowledge or technology, transfer of tacit knowledge, control of intellectual property and education of nuclear engineers.

The importance of tacit knowledge was first indicated by Polanyi (1958, 1966). According to him, the tacit knowledge is the subjective or physical knowledge like feeling, intuition, insight, experience or recognition, that is held in a person's mind and has typically not been captured or transferred in any form like language, formula or figures. The tacit knowledge was practically recognized by Nonaka (1991, 1995). His knowledge transformation model is called SECI (Socialization, Externalization, Combination and Internalization), which considers a spiraling knowledge process interaction between explicit knowledge and tacit knowledge.

Moreover, KM has two ways. One is the management by information technology for explicit knowledge (information) and the other is the management for tacit knowledge inside the organizational culture. The purpose of our approach is the enhancement of the both of the managements. In the KM, tacit knowledge is important because it is harder to cope with than explicit knowledge. Moreover, it is indicated that the application of the existing method on KM to the practical nuclear facilities has many kinds of difficulties. It is worth studying and implementing the methods at the realistic decommissioning installations with participations of experienced and skilled engineers.

Furthermore, we believe that a combination of advanced information technology and knowledge engineering makes the management system more efficient and practical. In Japan, four decommissioning projects of power reactors are going on in Japan. In the near future, several decommissioning projects will start, other than 6 units of Fukushima Daiichi. It is very important for Japan to integrate lessons-learned of decommissioning and share and transfer the 
knowledge for coming generations. The highly general knowledge can apply to other reactors. The facilitation of knowledge leads to the standardization of decommissioning eventually. It will enable totally rational and optimized decommissioning in Japan.

Moreover, the results of the study can contribute worldwide, because the number of decommissioning of power plants is increasing.

\section{Knowledge management activities and knowledge sources for decommissioning}

The data and information are sources of knowledge. The scoping of the data and information is necessary. The followings are international, domestic and plant specific information, documents and related systems, which are important and to be scoped.

\subsection{International activities and knowledge sources}

In the world, more and more experiences of the decommissioning are accumulated. IAEA, OECD/NEA and other international organizations collect useful information about the implementation of the decommissioning. By using a lot of practices of decommissioning, many kinds of the documents have been issued and contribute to the sharing and transferring the knowledge of decommissioning. Moreover, each country and each project has been accumulating information and knowledge. The following activities and knowledge sources should be the basis for the integration of $\mathrm{KM}$ for decommissioning.

\subsubsection{Activities in IAEA}

The general conference of the International Atomic Energy Agency (IAEA) indicated the importance of the nuclear knowledge in the general conference in 2002 (IAEA). In 2004, IAEA established a section for the KM and organized the first international meeting titled "Nuclear Knowledge Management: Strategies, Information Management and Human Resource Development” in Saclay, France. Fruitful discussion was done for basic concept, strategy, current activities, managing nuclear knowledge and information, human resources for the nuclear sector and networking education and training (IAEA, 2004). Moreover, the following workshops were held in Trieste, Italy in 2005 and Tokyo, Japan in 2006.

Based on the results of the activities, the IAEA issued more than 15 documents related to the NKM organized by the NKM section. Moreover, as important implementations of KM, activities for educational support and development of e-Learning systems are going on. For the area of decommissioning, specific document for KM of decommissioning is not issued so far. However, the increasing importance and characteristics are well recognized, the first consultancy meeting was held in Karlsruhe, Germany (IAEA, 2014a).

Other than KM, a variety of documents for decommissioning itself have been issued and safety standards were authorized as following document series;

$>$ Safety Standards Series, (e.g. General Safety Requirements Part 6),

$>$ Safety Report Series,

$>$ Technical Report Series,

$>$ Nuclear Energy Series,

$>$ TECDOCs.

Because the contents of these documents seem to be world common sense, they become the important basis of our KMS.

\subsubsection{Activities in OECD/NEA}

The activities of OECD/NEA concerning KM are complimentary to that of IAEA. It is carrying out international initiative of "Preservation of records, Knowledge and Memory (RK\&M) across Generations" for radioactive waste management with emphasis on geological disposal and on the post closure phase, which needs to be prepared while in operation (OECD/NEA, 2012). The first phase of the initiative has started in 2011 and ended in 2014. The phase-II project (2014-17) started so that the lessons may apply also to other forms of disposal.

For the decommissioning area, two groups play active roles in NEA. One is WPDD (Working Party on Decommissioning and Dismantling) which facilitates multilateral communication and information exchange among WPDD member countries, and the other is CPD (Co-operative Programme for Decommissioning), which is a platform for sharing technical and scientific information amongst major international decommissioning projects. Both of the groups are compiling documents with valuable knowledge regarding decommissioning, sometimes by organizing task groups of experts.

For example, the following documents were issued recently.

$>$ Radiological characterisation for decommissioning of Nuclear Installations (2013)

$>$ R\&D and Innovation Needs for Decommissioning Nuclear Facilities (2014)

$>$ Nuclear Site Remediation and Restoration during Decommissioning of Nuclear Installations (2014) 
These documents also contribute to the basis of our KMS.

\subsubsection{Other international knowledge sources}

The followings are the examples of other important information that should be considered for the knowledge sources of the management system.

$>$ Laws and regulatory documents of other countries, which have enough experience of decommissioning such as the United States, Germany, France etc.

$>$ Documents of USDOE for decommissioning and the EM (Environmental Management) program.

$>$ Documents of European Committee.

$>$ National reports for the Joint Convention on the Safety of Spent Fuel Management and on the Safety of Radioactive Waste Management.

$>$ Documents of international conferences for decommissioning.

$>$ Other documents of decommissioning by operators, research organizations, academia etc.

\subsection{Domestic Knowledge Sources in Japan}

\subsubsection{KM activities in Japan}

The importance of the KM is also recognized in Japan. Main activities of the utilities are based on the Quality Management System (QMS) for the operation and maintenance phase. Moreover, activities of education, training and human resource development are being promoted including decommissioning area. In the field of high level waste disposal, which requires very long time knowledge preservation, JAEA has developed a KM support system and it obtained good results (Makino, 2012). Especially after the Fukushima Daiichi accident, education and training became more important for the future decommissioning projects. However, the activities of KM should be intensified for this purpose.

\subsubsection{Decommissioning regulation system in Japan}

The regulation system itself is regarded as a final outcome of good KM.

Until 2005 in Japan, the regulation of the decommissioning of nuclear facilities was implemented by applying existing provisions in Law for the Regulations of Nuclear Source Material, Nuclear Fuel Material and Reactors (the Reactor Regulation Law), such as "notification of dismantling" or modification of "operational safety program", by the licensee. However, JPDR and the Tokai Power Station etc. and the development and application of dismantling technologies have progressed, thus the know-how for decommissioning has been accumulated through these processes.

Under such a circumstance, the Japanese regulatory body has investigated an appropriate regulatory system of decommissioning, based on the regulatory experiences of decommissioning of reactor facilities under the previous system. The investigation is conducted on the graded regulatory approach to cope with the progress of the decommissioning process, the diversity of each facility reflecting the experiences of decommissioning, and development of technologies in the near future.

On the basis of such recognition, the Reactor Regulation Law was amended in May, 2005 and the safety regulation for decommissioning of reactors and other facilities was updated. In addition, a graded regulation system was introduced. For example, now the annual periodic facility inspection by the regulatory body is not conducted when nuclear fuel materials are cleared from the facility. The outline of the decommissioning system in Japan is shown in Fig. 2 (Masuda, 2010). 


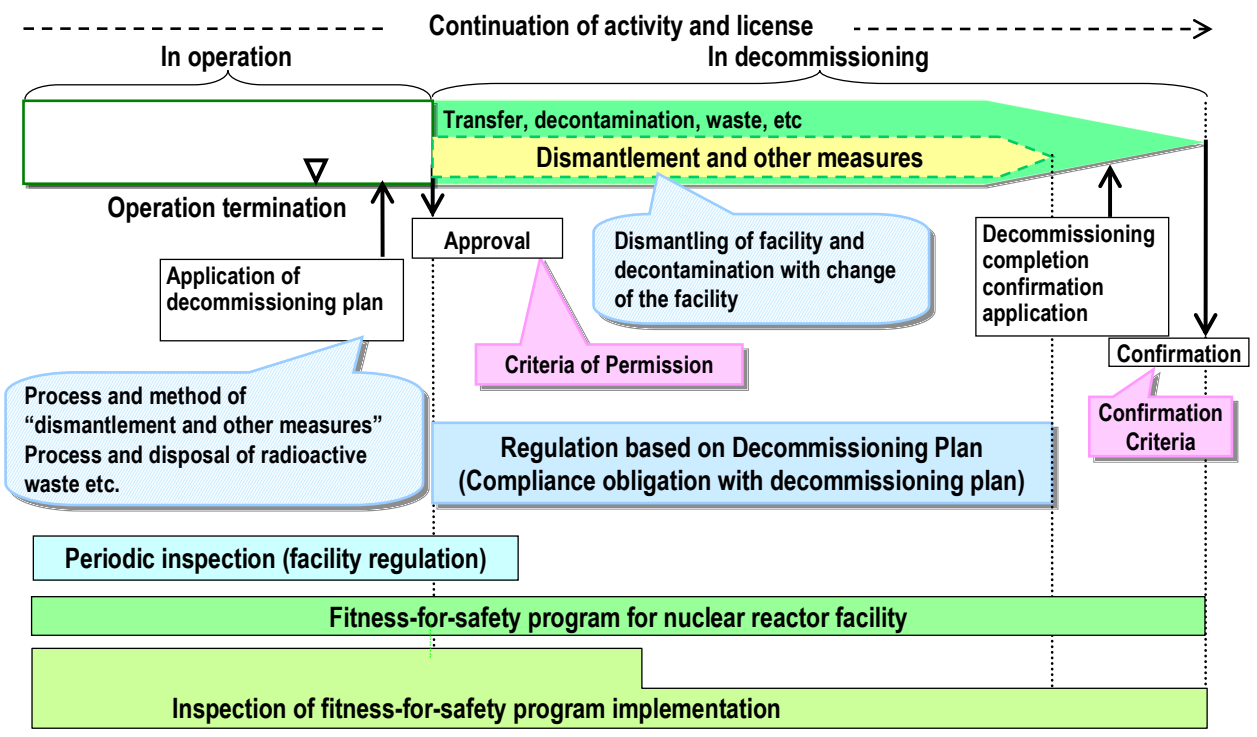

Fig. 2 Outline of decommissioning regulation in Japan

For the important information, the regulation requires specific records during the decommissioning process by Article 43-3-21 of the Reactor Regulation Law. Especially, the records which are necessary until the confirmation of the end of the decommissioning are listed in Table 1.

Table 1 Examples of records for the end of decommissioning (regulation rule)

\begin{tabular}{l|l}
\hline \multicolumn{1}{c|}{ Records } & \multicolumn{1}{c}{ Timing of Record } \\
\hline $\begin{array}{l}\text { Kind, activity, number and specific } \\
\text { weight of disposed waste, and date, } \\
\text { place and method of disposal }\end{array}$ & At the moment of disposal \\
\hline $\begin{array}{l}\text { Method of enclosure or solidification of } \\
\text { waste }\end{array}$ & $\begin{array}{l}\text { At the moment of enclosure or } \\
\text { solidification }\end{array}$ \\
\hline $\begin{array}{l}\text { Records of accident } \\
\text {-Time of occurrence and recovery }\end{array}$ & At the moment \\
-State of the accident and & \\
$\begin{array}{l}\text { countermeasures } \\
\text {-Cause of the accident }\end{array}$ & \\
-Treatment after the accident & \\
\hline $\begin{array}{l}\text { Work method and name of equipment } \\
\text { of decommissioning of the power station }\end{array}$ & $\begin{array}{l}\text { Every moment at the end of each } \\
\text { work process }\end{array}$ \\
\hline $\begin{array}{l}\text { Notes: data preservation term is until the confirmation of the end of the } \\
\text { decommissioning }\end{array}$
\end{tabular}

However, these records based on the law are not enough. Actually, the operator shall specify "Operational Safety Programs", which stipulates required records in detail. Moreover, under the QMS, a quality related records management manual shows how to preserve the records.

\subsubsection{Consensus standards in Japan}

It is important to incorporate academic or associated organization standards (consensus standards) to the regulation system, because it is very effective to introduce state-of-the-art technical knowledge for safety improvement. In other words, making these standards can contribute to the activity of KM. Japanese regulatory body has a policy to evaluate such consensus standards and the endorsed standards are used in the regulatory process properly.

In terms of the standardization of decommissioning regulation, the Atomic Energy Society of Japan compiled a standard for the decommissioning planning based on the experiences. Four standards are established concerning planning, implementation and seismic safety. Former NISA (Nuclear and Industrial Safety Agency) and former JNES (Japan Nuclear Energy Safety Organization) carried out technical evaluation of a standard of decommissioning planning, but it was not endorsed yet, because of the revision of the organizations and change of the circumstances after Fukushima Daiichi accident.

\subsubsection{Other domestic knowledge sources in Japan}

The followings are examples of important information in Japan which should be incorporated in the KMS. The system should provide necessary information at the best timing as required. 
Reports concerning decommissioning by the government of Japan (e.g. Atomic Energy Commission, former Nuclear Safety Commission, and NISA)

$>$ Reports concerning decommissioning by relevant organization (e.g. former JNES, former Nuclear Power Engineering Corporation (NUPEC), Institute of Applied Energy (IAE), Japan Atomic Energy Agency (JAEA) and Radwaste and Decommissioning Center (RANDEC)).

$>$ Documents of domestic conferences, journals for decommissioning.

$>$ Documents by operators of decommissioning

\subsection{Knowledge Sources in a Facility}

\subsubsection{Documents for the specific decommissioning facilities}

Each facility has own large amount of documents, manuals, related records and data from planning phase through end of the decommissioning. The followings are examples of them.

$>$ Application for reactor establishment

$>$ Construction plan

$>$ Decommissioning program

$>$ Operational safety program

$>$ Application for clearance

$>$ Quality assurance program

$>$ Other manuals of work processes

Moreover, many kinds of work support systems are used in the each plant and the systems treat a stack of data related to decommissioning. The followings are examples of the systems and data.

$>$ Maintenance management system (with trouble data, work data, component data, etc.)

$>$ Piping \& instrumentation diagram (P\&ID)

$>$ Single line diagram

$>$ Elementary wiring diagram

$>$ 3D-CAD data

$>$ Data of activity and contamination distribution

$>$ Radioactive waste data

$>$ Results of workload of dismantlement

For the purpose of effective decommissioning planning, the connection of these data is very useful. Figure 3 (Iguchi, 2004) shows an example of the data connection of the Fugen NPS.

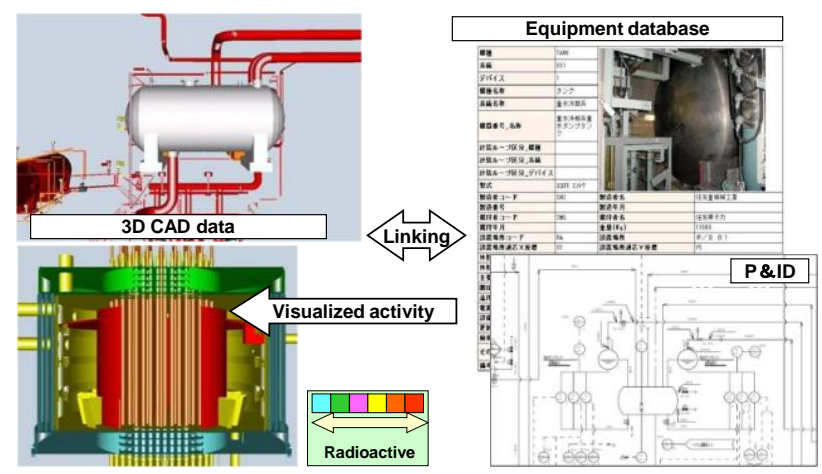

Fig. 3 Example of CAD system and data connection

Moreover, advanced usage of 3D data, for example, a Virtual Reality (VR) system or an Augmented Reality (AR) system is very useful for training and implementation of dismantlement. Figure 4 (Iguchi, 2004) shows an example of a VR system in the Fugen NPS. 


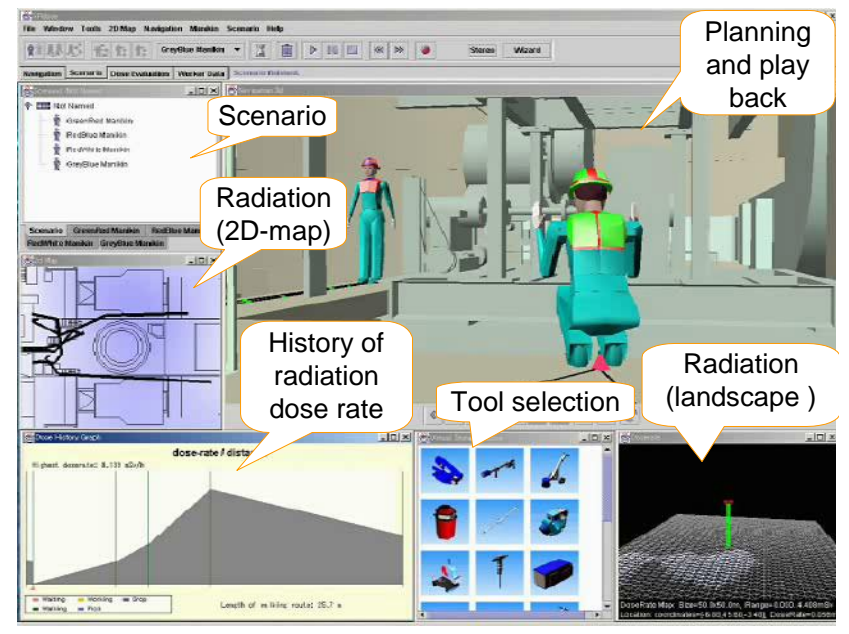

Fig. 4 Example of VR support system

Such kind of support systems can support efficient knowledge preservation, sharing and transfer. It is also useful material of e-learning for knowledge dissemination and education (Szőke, 2014).

\subsubsection{Human knowledge sources in a facility}

It is urgent to extract tacit knowledge from retiring or aging staff. They have, for example, following knowledge.

$>$ Knowledge about facilities

$>$ General knowledge of plant or nuclear engineering

$>$ Knowledge of what to investigate if necessary

$>$ Knowledge of who to ask if necessary

$>$ Know-how of trouble shooting

$>$ Wisdom based on the life experience

The valuable knowledge should be acquired by documenting, questionnaires, interviews etc. and they should be converted into explicit knowledge as much as possible.

\subsubsection{Difficulty of acquisition and transfer of tacit knowledge}

As mentioned above, there is knowledge which can be externalized as explicit knowledge. However, there still exists tacit knowledge which cannot be transformed into explicit status.

$>$ Even by interview or questionnaire, it is difficult to specify the knowledge.

$>$ Trouble shooting know-how is just produced when the situation occurred.

$>$ There is wisdom beyond knowledge, which is based on personal life experience.

$>$ In an organization, there is so-called collective intelligence.

However, this tacit knowledge should be transferred in some way as much as possible.

For example:

$>$ Case study or simulation of the trouble shooting

$>$ Documenting of historical information of the facility, even if it does not seem to be valuable for the decommissioning at the present moment

$>$ A special on-the-job-training by retirees to employees

$>$ System to asking retirees about the related historical information about the facility

$>$ Periodical meeting or reunion with retirees

\section{Integration plan of KMS}

As shown in chapter 3, three-step integration of KMS was proposed. So far, a plant under decommissioning is performing activities based on the "decommissioning plan", which was approved by the regulatory authority in Japan. In this situation, KM is possibly implicitly functioning. However, the situation may be changed when skilled employees retire. The KMS should be based on the existing implicit KMS. The followings are more minute integration plan of KMS.

\subsection{Establishment of knowledge acquisition method necessary for decommissioning 6.1.1 Arrangement of data and information}


The data, information and knowledge which are necessary for decommissioning track back to design, construction, operation and maintenance period. Moreover, investigation data and information of decommissioning from the planning stage to the present stage are required. As mentioned above, not all the data and information are necessary.

Furthermore, there exist data, information and knowledge from international or domestic decommissioning results or research outcomes. This includes documents of international organizations such as IAEA or OECD/NEA shown in above. The documents related to a specific plant are important knowledge sources. Laws and technical standards seem to be embodied knowledge.

The systems such as QMS, information management system, and work support system can be a part of KMS. We should list up the data, information and knowledge sources and arrange them according to the importance in terms of the KMS, and specify indispensable items.

\subsubsection{Systematization of data and information}

The specified knowledge sources are infrastructure for implementing the decommissioning and become important basis for construction of KMS. Inside the large amount of data and information, valuable knowledge underlies. It should be externalized, organized and systematized for advanced utilization. For this purpose, rules and methods to extract necessary records and information from the primary information should be established. Formulation of a kind of taxonomy for decommissioning will be helpful.

\subsubsection{Establishment of method of knowledge extraction}

Based on the classification by the above mentioned taxonomy, a method of quick accessing necessary information should be established by using data mining, document analysis and AI technologies in order to specify and retrieve required records and information for decommissioning implementation from large amount of data and information source. This leads to the linking method of extraction of essential knowledge for decommissioning.

\subsubsection{Organization of historical documents and experiences story}

Historical documents, records and experiences of a facility are possibly useful for decommissioning in some way. It can be helpful communication facts between retirees and present employees. For this purpose, historical facts and chronological table should be made, introducing experience story or episodes of the engineers or employees who were engaged in design, construction, operation and maintenance in the past, and it should be referred effectively.

\subsection{Formulation of knowledge acquisition from experienced engineers}

\subsubsection{Data base construction of experienced employees}

The knowledge, know-how and experiences of engineers or employees who engaged in design, construction, operation and maintenance or decommissioning planning and implementation of dismantlement are useful for effective decommissioning. For the long term decommissioning project, these knowledge etc. should be effectively retrieved from them and shared with others and transferred to the future generation.

For this purpose, personnel records of them related to the plant should be listed and cataloged. The data should include retirees and related engineers of vendors as well as present employees if necessary. The technical history related to decommissioning should be made as data base and the data should be accessed by the present employees. This function leads to know who-to-ask in the decommissioning work.

Moreover, each employee can add his own knowledge and know-how to the data system as well as his technical history for the future knowledge externalization.

\subsubsection{Establishment of method for extraction of knowledge and know-how from experienced employees}

The knowledge and know-how of experienced employees are partly externalized by the information circulation of catalogued data and information. Moreover, deep knowledge should be explicit one by interview and questionnaire to more skilled employees. This method should be established.

On the other hand, it may be partly possible to make documents about knowledge, but direct question to the employee is not practical. Even if the employee cannot recall valuable experience, he/she still has knowledge. For instance, the employee must have solved some problems when they occurred, by using "wisdom" based on a variety of experiences in the past. This means taking out good practices of problem solution by the past storytelling or simulation of problem solution may lead to the effective knowledge acquisition.

\subsection{Construction of KM support system for decommissioning}

The extracted, externalized or combined knowledge by above mentioned approach should be effectively utilized and enhanced in the decommissioning implementation phase. For this purpose, construction of support system for KM and 
method of knowledge accumulation in the decommissioning work process is proposed.

\subsubsection{Enhancement of communication between present employees}

Communication activities, such as regular meetings, information exchange via intranet or e-mail are basis of the knowledge exchange in a plant. Based on the existing communication infrastructure, enhancement activities should be carried out for knowledge socialization. For example, application of Social Networking Service (SNS) inside the organization said to be an effective tool for improving communication and KM. Such system can hold personnel data base and automatically accumulate knowledge obtained during the daily work. Moreover, it is possible to load valuable technical information and questions raised by users and their answers. In this way, the system becomes knowledge accumulation and communication system without much effort.

\subsubsection{Enhancement of knowledge internalization of present employees}

The communication via computer system is not enough and face-to-face communication is still necessary. Then, activities such as study meeting of present employees or discussion between different generations are necessary for knowledge internalization.

\subsubsection{Knowledge transfer support from retirees}

After retiring of experienced employees, in some cases, the present employees need help of retirees. For this situation, retirees should join the above mentioned inside SNS even after retirement and give opinions or suggestions for the problem solution. This requires consent of retirees, but it is very effective to make up the knowledge gap.

\subsubsection{Method of QMS introduction to KM}

Many nuclear installations operate a certified QMS to the requirements of ISO 9001. We can find some similarity between QMS and KMS. Actually, the QMS partly manages important knowledge regarding quality and plant safety. It is possible to integrate KM strategies, processes and systems with the existing management system or invent a system for KM based on the ISO philosophy (IAEA, 2012). In this case, the enhanced management system collects important knowledge and accumulates it as documents or records semi-automatically, because the knowledge is produced in daily work process which is also related to quality management.

However, it may be difficult to merge these systems for two purposes because it may become complex and heavy system. An independent similar system can be an alternative solution. We have to introduce this management system very carefully.

\subsubsection{Establishment of knowledge transfer education}

Many kinds of educational activities are carried out at the decommissioning plant. In terms of KM, these activities should be enhanced. For example, it is desirable that retiring employees have special or regular lectures about the knowledge about design, construction, pre-service inspection, refurbishment in the past which younger employees are not familiar with, or historical lessons learned which is relevant to or even not to decommissioning project.

Moreover, on-the-job training is necessary for the new comers by senior associates, for example one year until they can work by themselves. A skilled employee who is soon retiring can be a better trainer. If possible, one by one training with frequent and deep communication would be effective in order to inherit valuable knowledge which is difficult to externalize.

\subsubsection{Enhancement of information access system}

There are challenges how to provide the employees with large amount of data, information and knowledge on the good timing with minimum quantity. For this purpose, effective access system should be established. It should arrange and extract necessary information from a pile of data and information, show systematically to the users. Usually, an intranet with data base system is used for this purpose, but the usability should be improved in terms of KM. The improvement should include existing work flow or documentation systems.

\subsubsection{Advanced information system for KM support}

The decommissioning of a plant is a process of removing equipment and components. In other words, decommissioning data can be linked with each component. Moreover, each component or equipment has historical data such as operation, maintenance, activity, secondary contamination etc. Not only these data but also additional information and even knowledge can be linked with the equipment and components. If a 3D-CAD system is available, the data can be browsed on the CAD system and it may be easily understandable to the user.

Furthermore, a VR system can provide the workers with the information more realistically in the training or an AR system can be a guide system in the dismantlement field. Development of these systems should be proposed 
considering cost-performance.

\subsubsection{Information exchange framework with other decommissioning facilities}

Knowledge and information of decommissioning is generated everyday not only in the specific plant but also internationally. This information should be introduced to the knowledge base and reflected to the decommissioning project. For this purpose, a periodic searching process of outside information should be systematized, which is similar the activities of trouble information reflection during the operation. Moreover, information exchange activities among related organizations are desirable.

\subsubsection{Standardization of decommissioning knowledge}

The information and knowledge accumulated at the decommissioning plant can be reused to other decommissioning project. This knowledge should be compiled as general knowledge and it should be included in the standard document. For this purpose, activities to extract important and general knowledge from bulk of knowledge are necessary.

\section{Conclusions}

$\mathrm{KM}$ is indispensable and important for decommissioning of nuclear facilities because of the extension of the period of the project and skilled employees retirement. KM should be cost effective, with low risk, because decommissioning is unproductive work. Knowledge of decommissioning is not the same as that of operational period, and then we have to specify the necessary data, information and knowledge for the project.

Based on the quality management, record management, rule-making and system construction is crucial activity for the KM. Information technology is necessary for the management of the decommissioning project and it will substantially contribute to the KM. Moreover, advanced information technology such as 3D-CAD, VR and AR has possibility to enhance KM.

We have to effectively utilize valuable explicit and tacit knowledge of retiring employee. It is necessary to develop the method to realize it. Accordingly, an integration plan of KM for decommissioning facilities was proposed and discussed. This plan will be implemented and tested in the real decommissioning plant in the future.

\section{References}

Ehlert, A., Implementation of Knowledge Management in the Decommissioning of Nuclear Power Stations of E.ON Kernkraft Gmbh, IAEA-CN-153/2/P/05 (2007).

IAEA, GC(46)/RES/11 (2002).

IAEA, Record Keeping for the Decommissioning of Nuclear Facilities Guidelines and Experience, TRS-411 (2003).

IAEA, International Conference on Managing Nuclear Knowledge Strategies and Human Resources Development, Summary of an International Conference (2004).

IAEA, Knowledge Management for Nuclear Research and Development Organizations, TECDOC-1675 (2012).

IAEA, Nuclear Knowledge Management e-Bulletin No.3 (2014a).

IAEA, Decommissioning of Facilities, General Safety Requirements GSR Part 6 (No.GSR Part 6) (2014b).

Iguchi, Y., et al., Development of decommissioning engineering support system (DEXUS) of the Fugen Nuclear Power Plant, Journal of Nuclear Science and Technology, Vol.41(3) (2004), pp367-375.

Ishikura, T. and Hirusawa, S., Technology Preservation and Transfer for Nuclear Power Plant Decommissioning, ANS DD\&R (2010).

Kirschnick, F. and Engelhardt, S., Knowledge Management for the Decommissioning of Nuclear Power Plants, IAEA-CN-123/03/O/01 (2004).

Makino, H., et al., A Challenge on development of an advanced Knowledge Management System (KMS) for radioactive waste disposal; Moving from theory to practice, InTech, New Research on Knowledge Management Technology (2012), pp165-184.

Masuda, Y., et al., Status of the Support Researches for the Regulation of Nuclear Facilities Decommissioning, Proceedings of the 13th International Conference on Environmental Remediation and Radioactive Waste Management (2010), Paper No. ICEM2010-40245.

Nonaka, I., The knowledge creating company, Harvard Business Rev., 69 (1991), pp.96-104.

Nonaka, I. and Takeuchi, H., The knowledge-creating company: How Japanese companies create the dynamics of innovation, Oxford University Press, Inc. (1995).

OECD/NEA, Progress Report of the Project on Preservation of Records Knowledge and Memory (RK and M) Across 
Generations (2012).

Polanyi, M., Personal Knowledge, Chicago: The University of Chicago Press (1958).

Polanyi, M., The tacit dimension, London: Routledge \& Kegan Paul (1966).

Szőke, I., et al., Comprehensive support for nuclear decommissioning based on 3D simulation and advanced user interface technologies, Journal of Nuclear Science and Technology, Vol.51 (2014). 